\title{
Experimental Investigation and Theoretical Modeling of Nanosilica Activity in Concrete
}

\author{
Han-Seung Lee, ${ }^{1}$ Hyeong-Kyu Cho, ${ }^{1}$ and Xiao-Yong Wang ${ }^{2}$ \\ ${ }^{1}$ School of Architecture \& Architectural Engineering, Hanyang University, Ansan 425-791, Republic of Korea \\ ${ }^{2}$ Department of Architectural Engineering, College of Engineering, Kangwon National University, \\ Chuncheon 200-701, Republic of Korea
}

Correspondence should be addressed to Xiao-Yong Wang; wxbrave@kangwon.ac.kr

Received 18 May 2014; Revised 16 July 2014; Accepted 27 July 2014; Published 11 August 2014

Academic Editor: Nageh K. Allam

Copyright (C) 2014 Han-Seung Lee et al. This is an open access article distributed under the Creative Commons Attribution License, which permits unrestricted use, distribution, and reproduction in any medium, provided the original work is properly cited.

\begin{abstract}
This paper presents experimental investigations and theoretical modeling of the hydration reaction of nanosilica blended concrete with different water-to-binder ratios and different nanosilica replacement ratios. The developments of chemically bound water contents, calcium hydroxide contents, and compressive strength of Portland cement control specimens and nanosilica blended specimens were measured at different ages: 1 day, 3 days, 7 days, 14 days, and 28 days. Due to the pozzolanic reaction of nanosilica, the contents of calcium hydroxide in nanosilica blended pastes are considerably lower than those in the control specimens. Compared with the control specimens, the extent of compressive strength enhancement in the nanosilica blended specimens is much higher at early ages. Additionally, a blended cement hydration model that considers both the hydration reaction of cement and the pozzolanic reaction of nanosilica is proposed. The properties of nanosilica blended concrete during hardening were evaluated using the degree of hydration of cement and the reaction degree of nanosilica. The calculated chemically bound water contents, calcium hydroxide contents, and compressive strength were generally consistent with the experimental results.
\end{abstract}

\section{Introduction}

Scientists have considered nanomaterials to be the most promising materials of the 21st century. In recent years, considerable attention has been focused on civil engineering applications for nanomaterials because nanoparticles possess many unique properties due to their small size, such as large specific surface areas and high activity [1].

Many experimental studies have investigated the influence of adding nanosilica on the properties of concrete. Li et al. [2] showed that the compressive and flexural strengths of cement mortars mixed with nanoparticles measured on the 7 th day and the 28th day were higher than those of a plain cement mortar. Zhang and $\mathrm{Li}$ [3] found that the addition of nanoparticles refines the pore structure of concrete and enhances the resistance of concrete to chloride penetration. Ji [4] found that the microstructure of concrete containing nano- $\mathrm{SiO}_{2}$ is more uniform and compact than that of normal concrete and that the incorporation of nano- $\mathrm{SiO}_{2}$ can improve the resistance of concrete to water penetration.
Jo et al. [5] found that nanoparticles are more effective at enhancing strength than silica fume and that nanoscale $\mathrm{SiO}_{2}$ functions not only as a filler to improve the microstructure but also as an activator to promote pozzolanic reactions.

Although numerous experimental studies have investigated the physical and chemical properties of nanosilica blended concrete, research on the modeling of hydration of nanosilica blended concrete is very limited. Some existing hydration models [6-10] are only valid for traditional mineral admixture blended concretes, such as slag blended concrete, fly ash blended concrete, and silica fume blended concrete. To fill this knowledge gap, this paper proposes a blended cement hydration model that considers both the hydration reaction of cement and the pozzolanic reaction of nanosilica. The properties of nanosilica blended concrete during hardening, such as the content of chemically bound water, the content of calcium hydroxide, and the development of compressive strength, were evaluated using the hydration degree of cement and the reaction degree of nanosilica. 


\section{Hydration Model of Portland Cement}

Tomosawa et al. [11, 12] developed a shrinking-core model to simulate the development of cement hydration. This model is expressed as a single equation that consists of three coefficients: $k_{d}$ is the reaction coefficient in the induction period; $D_{e}$ is the effective diffusion coefficient of water through the $\mathrm{C}-\mathrm{S}-\mathrm{H}$ gel; and $k_{r}$ is a coefficient of the reaction rate of cement, as shown in (1) below. These coefficients determine the rate of mass transport through the initial shell layer, the rate of the phase boundary reaction process, and the rate of the diffusion-controlled process. The modeled cement particles are assumed to be spheres surrounded by hydration product. Based on this theory, the rate of cement hydration is derived as follows:

$$
\begin{aligned}
& \frac{d \alpha}{d t}= \frac{3\left(S_{w} / S_{0}\right) \rho_{w} C_{w-\text { free }}}{\left(v+w_{g}\right) r_{0} \rho_{c}} \\
& \times\left(( 1 ) \left(\left(\frac{1}{k_{d}}-\frac{r_{0}}{D_{e}}\right)+\frac{r_{0}}{D_{e}}(1-\alpha)^{-1 / 3}\right.\right. \\
&\left.\left.+\frac{1}{k_{r}}(1-\alpha)^{-2 / 3}\right)^{-1}\right)
\end{aligned}
$$

where $\alpha$ is the degree of cement hydration; $v$ is the stoichiometric ratio by mass of water to cement $(=0.25) ; w_{g}$ is the physically bound water in $\mathrm{C}-\mathrm{S}-\mathrm{H}$ gel $(=0.15) ; \rho_{w}$ is the density of water; $C_{w \text {-free }}$ is the amount of water at the exterior of the $\mathrm{C}-\mathrm{S}-\mathrm{H}$ gel; $r_{0}$ is the radius of unhydrated cement particles $\left(r_{0}=3 /\left(S \rho_{c}\right)\right.$, where $S$ and $\rho_{c}$ represent the Blaine surface area and density of the cement, resp.); $S_{w}$ is the effective surface area of the cement particles in contact with water; and $S_{0}$ is the total surface area if the surface area develops unconstrained.

The reaction coefficient $k_{d}$ is assumed to be a function of the degree of hydration, as shown in (2), where $B$ and $C$ are the coefficients that determine this factor; $B$ controls the rate of the initial shell formation and $C$ controls the rate of the initial shell decay. Consider

$$
k_{d}=\frac{B}{\alpha^{1.5}}+C \alpha^{3} .
$$

The effective diffusion coefficient of water is affected by the tortuosity of the gel pores and by the radii of the gel pores in the hydrate. This phenomenon can be described as a function of the degree of hydration and is expressed as follows:

$$
D_{e}=D_{e 0} \ln \left(\frac{1}{\alpha}\right) .
$$

In addition, free water in the capillary pores is depleted as the hydration of cement minerals progresses. Some water is bound in the gel pores, and this water is not available for further hydration, which is an effect that must be taken into consideration during every step of the hydration process. Therefore, the amount of water in the capillary pores $C_{w \text {-free }}$ is expressed as a function of the degree of hydration in the previous step, as shown in

$$
C_{w-\text { free }}=\frac{W_{0}-0.4 * \alpha * C_{0}}{W_{0}},
$$

where $C_{0}$ and $W_{0}$ are the mass fractions of cement and water in the mix proportion.

The effect of temperature on these reaction coefficients is assumed to follow Arrhenius's law, as shown in

$$
\begin{aligned}
B & =B_{20} \exp \left(-\beta_{1}\left(\frac{1}{T}-\frac{1}{293}\right)\right), \\
C & =C_{20} \exp \left(-\beta_{2}\left(\frac{1}{T}-\frac{1}{293}\right)\right), \\
k_{r} & =k_{r 20} \exp \left(-\frac{E}{R}\left(\frac{1}{T}-\frac{1}{293}\right)\right), \\
D_{e} & =D_{e 20} \exp \left(-\beta_{3}\left(\frac{1}{T}-\frac{1}{293}\right)\right),
\end{aligned}
$$

where $\beta_{1}, \beta_{2}, E / R$, and $\beta_{3}$ are temperature sensitivity coefficients and $B_{20}, C_{20}, k_{r 20}$, and $D_{e 20}$ are the values of $B, C, k_{r}$, and $D_{e}$ at $20^{\circ} \mathrm{C}$, respectively.

Using the proposed Portland cement hydration model, Tomosawa et al. [11, 12] evaluated the heat evolution rate, chemically bound water content, and compressive strength of hardening concrete. However, note that Tomosawa's model is only valid for Portland cement. To model the hydration of nanosilica blended concrete, a reaction model for nanosilica should be constructed and the mutual interactions between cement hydration and the nanosilica reaction should be clarified.

\section{Hydration Model for Cement Blended with Nanosilica}

3.1. The Amount of Calcium Hydroxide (CH) during the Hydration Process. During the hydration of Portland cement paste, the amount of calcium hydroxide is directly proportional to the degree of hydration of cement [11]. Furthermore, Papadakis [10] proposed that the amount of calcium hydroxide in cement-nanosilica blends during hydration can be determined with the following equation:

$$
\mathrm{CH}=\mathrm{RCH}_{\mathrm{CE}} * C_{0} * \alpha-\mathrm{RCH}_{\mathrm{SF}} * \alpha_{\text {silica }} * m_{\text {silica0 }} .
$$

In (6), $\mathrm{RCH}_{\mathrm{CE}}$ is the mass of calcium hydroxide produced from the hydration of cement; $\mathrm{RCH}_{\mathrm{SF}}$ is the mass of calcium hydroxide consumed during the pozzolanic reaction of nanosilica; $\alpha_{\text {silica }}$ is the degree of hydration of the glass (active) phase of nanosilica; and $m_{\text {silica }}$ is the mass of nanosilica in the mixing proportion. In this equation, the term $\mathrm{RCH}_{\mathrm{CE}} *$ $C_{0} * \alpha$ considers the production of calcium hydroxide from the hydration of cement and the term $-\mathrm{RCH}_{\mathrm{SF}} * \alpha_{\text {silica }} *$ $m_{\text {silicao }}$ considers the consumption of calcium hydroxide during the pozzolanic reaction. The value of $\mathrm{RCH}_{\mathrm{CE}}$ is related to the chemical compositions of Portland cement and can be obtained from the experimentally determined calcium hydroxide content and chemically bound water content in Portland cement paste. The value of $\mathrm{RCH}_{\mathrm{SF}}$ can be derived from the experimentally determined calcium hydroxide contents in Portland cement paste and nanosilica blended cement paste.

Similar to the hydration of cement, as the pozzolanic reaction proceeds, water will be physically adsorbed in the 
nanosilica hydration products. Lura et al. [13] proposed that, for the silica fume pozzolanic reaction, when $1 \mathrm{~g}$ of silica fume reacts, $0.5 \mathrm{~g}$ of gel water and $0 \mathrm{~g}$ of chemical water will be consumed. Hence, the masses of capillary water and chemically bound water during the hydration of cement-nanosilica blends can be rewritten as in the following equations:

$$
\begin{aligned}
W_{\text {cap }} & =W_{0}-0.4 * C_{0} * \alpha-0.5 * \alpha_{\text {silica }} * m_{\text {silica } 0}, \\
W_{\text {chem }} & =0.25 * C_{0} * \alpha
\end{aligned}
$$

where $W_{\text {cap }}$ and $W_{\text {chem }}$ are the masses of capillary water and chemically bound water, respectively. In (7a) and (7b), the term $0.4 * C_{0} * \alpha$ considers the reduction of capillary water due to cement hydration. The term $0.5 * \alpha_{\text {silica }} * m_{\text {silica } 0}$ considers the reduction of capillary water due to the pozzolanic reaction [13].

3.2. Simulation of the Pozzolanic Reaction in Cement-Nanosilica Blends. Because of the high specific surface area of nanosilica and its considerable pozzolanic activity, in this paper, it is assumed that the hydration of nanosilica includes two processes: phase-boundary reaction process and diffusion process. Considering these points, based on the method proposed by Saeki and Monteiro [14], the nanosilica hydration equation can be written as

$$
\begin{aligned}
\frac{d \alpha_{\text {silica }}}{d t}= & \frac{m_{\mathrm{CH}}(t)}{m_{\text {silica } 0}} \frac{3 \rho_{w}}{v_{s i} r_{s i 0} \rho_{s i}} \\
& \times\left(( 1 ) \left(\frac{r_{\text {sio }}}{D_{e s i}}\left(1-\alpha_{\text {silica }}\right)^{-1 / 3}-\frac{r_{s i 0}}{D_{e s i}}\right.\right. \\
& \left.\left.+\frac{1}{k_{r s i}}\left(1-\alpha_{\text {silica }}\right)^{-2 / 3}\right)^{-1}\right), \\
D_{e s i}= & D_{e s i 0} * \ln \left(\frac{1}{\alpha_{\text {silica }}}\right),
\end{aligned}
$$

where $m_{\mathrm{CH}}(t)$ is the mass of calcium hydroxide in a unit volume of hydrating cement-nanosilica blends and can be obtained from (6). $v_{s i}$ is the stoichiometric ratio of $\mathrm{CH}$ to nanosilica by mass. $r_{s i 0}$ is the radius of the nanosilica particles. $\rho_{s i}$ is the density of nanosilica. $D_{e s i 0}$ is the initial diffusion coefficient, and $k_{r s i}$ is the reaction rate coefficient.

The influence of temperature on hydration is considered using the Arrhenius law, as in the following equations:

$$
\begin{aligned}
& k_{r s i}=k_{r s i 20} \exp \left[-\frac{E_{s i}}{R(1 / T-1 / 293)}\right], \\
& D_{e s i 0}=D_{e s i 20} \exp \left[-\beta_{e s i}\left(\frac{1}{T}-\frac{1}{293}\right)\right],
\end{aligned}
$$

where $k_{r s i 20}$ and $D_{e s i 20}$ are reaction coefficients at $20^{\circ} \mathrm{C}$ and $E_{s i} / R$ and $\beta_{\text {esi }}$ are activation energies.

When nanosilica is incorporated in concrete, two possible reasons may be used to explain the change in the hydration process. The first is the pozzolanic reaction of amorphous phases in nanosilica, and the second is the influence of nanosilica on the hydration of cement. In the current paper, a new model is proposed that can describe the pozzolanic reaction between calcium hydroxide and nanosilica. In addition, the influence of nanosilica on the hydration of cement is considered through the amount of capillary water (7a) and the dilution effect (4). By using the proposed model, the reaction degrees of cement and nanosilica can be determined as functions of the curing time. Furthermore, the properties of nanosilica blended concrete during hardening can be evaluated from the reaction degrees of cement and nanosilica.

In this study, (1) through (8a), (8b), (8c), and (8d) are used to model the hydration of nanosilica blended concrete. For nanosilica blended concrete, the hydration of Portland cement and the pozzolanic reaction of nanosilica occur simultaneously. The hydration of Portland cement is simulated using (1) to (5), which were proposed by Tomosawa et al. $[11,12]$. The pozzolanic reaction of nanosilica is described using $(8 \mathrm{a})$ to $(8 \mathrm{~d})$, which are the authors' original work. The interactions between the hydration of cement and the pozzolanic reaction of nanosilica are considered using (6) to (7a) and (7b), which are also original work of the authors.

Note that Tomosawa's model is only valid for Portland cement; this model is not valid for nanosilica blended cement because of the coexistence of Portland cement hydration and the pozzolanic reaction of nanosilica. To model the hydration of nanosilica blended concrete, a new reaction model of nanosilica is constructed, and the mutual interactions between cement hydration and the nanosilica reaction are clarified.

An outline of the modeling process is shown in Figure 1. The proposed procedure considered the effects of nanosilica replacement ratios, water-to-binder ratios, and curing temperatures on the hydration of nanosilica blended concrete. At each time step, the calcium hydroxide contents, capillary water contents, chemically bound water contents, gel-space ratio, and compressive strength of hardening nanosilica blended concrete are determined using the cement hydration degree and the nanosilica reaction degree.

\section{Experimental Investigation and Theoretical Verification of the Hydration Model}

To verify the proposed model, a series of experimental investigations were conducted to investigate the properties of nanosilica blended paste. The cementitious materials used were ordinary Portland cement (OPC) and nano- $\mathrm{SiO}_{2}$. The chemical composition of the Portland cement is shown in Table 1, and the physical and chemical properties of the nanosilica are shown in Table 2. The $\mathrm{SiO}_{2}$ purity of the nanosilica is 0.999 , and the mean particle size of the nanosilica is 15 nanometers. The mixing proportions of the cement-nanosilica paste specimens are shown in Table 3. The influences of the water-to-binder ratios (0.3 and 0.5$)$ and nanosilica replacement ratios $(0.03$ and 0.06$)$ on the hydration of Portland cement were investigated. 


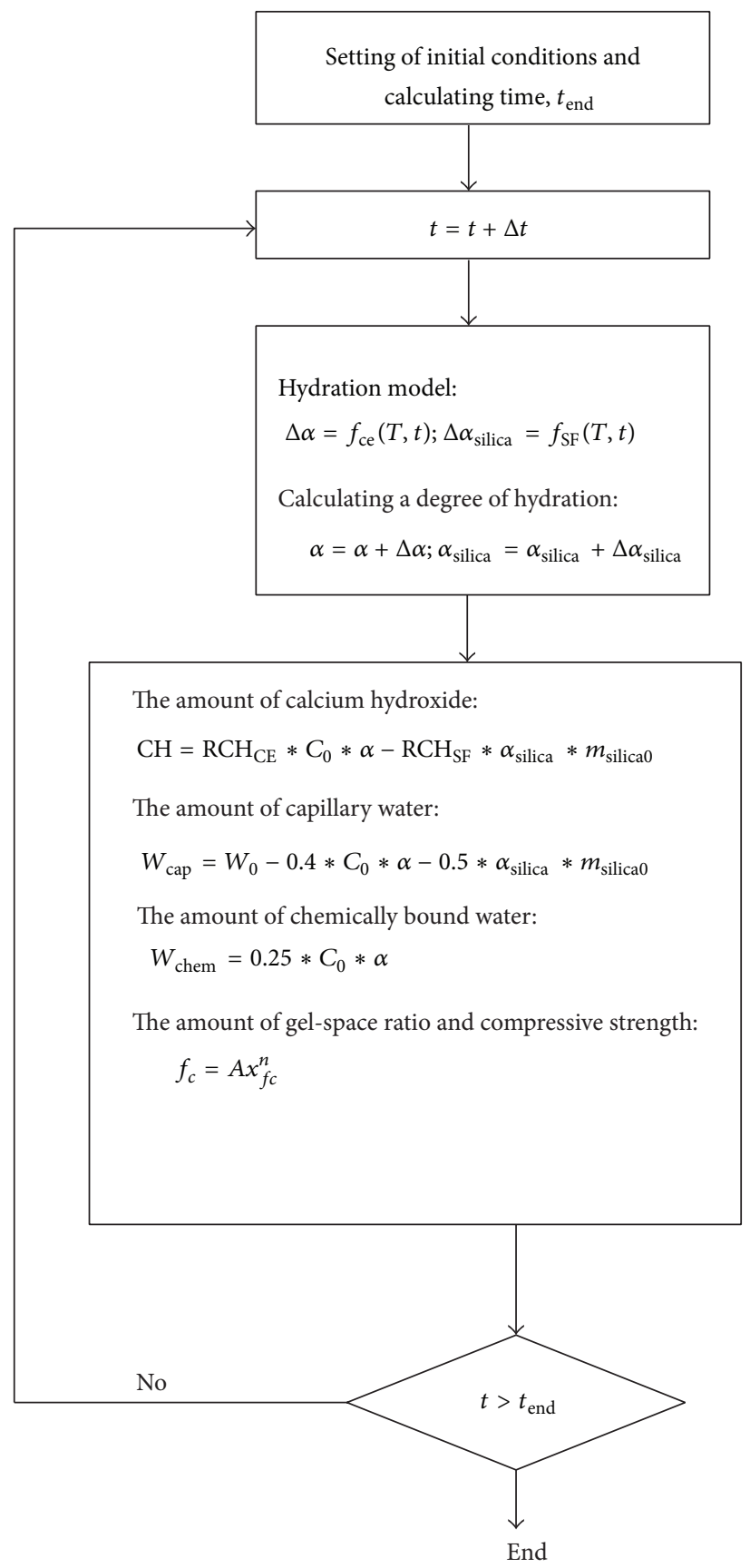

FIgURE 1: The outline of modeling.

TABle 1: Mineral compositions of Portland cement.

\begin{tabular}{lccccccccccc}
\hline \multicolumn{4}{c}{ Mineral composition (\% by mass) } & \multicolumn{4}{c}{ Chemical composition (\% by mass) } \\
$\mathrm{C}_{3} \mathrm{~S}$ & $\mathrm{C}_{2} \mathrm{~S}$ & $\mathrm{C}_{3} \mathrm{~A}$ & $\mathrm{C}_{4} \mathrm{AF}$ & $\mathrm{SiO}_{2}$ & $\mathrm{Al}_{2} \mathrm{O}_{3}$ & $\mathrm{Fe}_{2} \mathrm{O}_{3}$ & $\mathrm{CaO}$ & $\mathrm{MgO}$ & $\mathrm{SO}_{3}$ & $\mathrm{~K}_{2} \mathrm{O}$ & $\mathrm{Na}_{2} \mathrm{O}$ \\
\hline 58.48 & 11.16 & 8.83 & 8.74 & 19.29 & 5.16 & 2.87 & 61.68 & 4.17 & 2.53 & 0.92 & 0.21 \\
\hline
\end{tabular}

The specimens were prepared according to the Korean Agency for Technology and Standard KSL 5109 (testing method for mechanical mixing of hydraulic cement paste and mortars of plastic consistency). A rotary mortar mixer was used to prepare specimens. To uniformly disperse nanosilica particles, after dissolving the AE agent in water, nanosilica was added to water and mixed at a high speed for approximately 2 minutes. Then, the cement was added into the mixer and mixed for approximately 1 minute. After preparing the paste specimens $(10 \mathrm{~cm} \times 10 \mathrm{~cm} \times 40 \mathrm{~cm})$, the specimens were 
TABle 2: Properties of nanosilica.

\begin{tabular}{lccc}
\hline $\begin{array}{l}\text { Particle size } \\
(\mathrm{nm})\end{array}$ & $\begin{array}{c}\text { Specific surface } \\
\text { area }\left(\mathrm{m}^{2} / \mathrm{g}\right)\end{array}$ & $\begin{array}{c}\text { Density } \\
\left(\mathrm{g} / \mathrm{cm}^{3}\right)\end{array}$ & $\begin{array}{c}\mathrm{SiO}_{2} \\
\text { purity }(\%)\end{array}$ \\
\hline 15 & 250 & 0.05 & 99.9 \\
\hline
\end{tabular}

sealed and cured in a chamber at $20^{\circ} \mathrm{C}$ until they reached the testing age.

The compressive strength, chemically bound water content, and calcium hydroxide content were measured at different ages: 1 day and 3, 7, 14, and 28 days.

The compressive strength tests were performed according to the Korean Agency for Technology and Standard KSL 2426 (standard test method for compressive strength of mortar grout). The dimensions of the test specimens were $10 \mathrm{~cm}$ $\times 10 \mathrm{~cm} \times 40 \mathrm{~cm}$. The compressive strength was measured using a universal testing machine with a loading rate of $0.4 \mathrm{~N} / \mathrm{mm}^{2} / \mathrm{s}$. For each mixing proportion, three specimens were tested, and the compressive strength was determined from the average value of three specimens.

The fractured pieces after the compression test were preserved for the calcium hydroxide tests and chemically bound water tests. To stop the hydration reactions, the samples were soaked in acetone for 7 days and were then placed in a vacuum desiccator overnight to remove the acetone. These samples were further dried at $60^{\circ} \mathrm{C}$ in an oven for 24 hours and were ground to pass through a $150 \mu \mathrm{m}$ sieve.

To determine the content of chemically bound water, $1 \mathrm{~g}$ of the hydrated sample was dried in an oven at $105^{\circ} \mathrm{C}$ for 3 hours and was then ignited at $1050^{\circ} \mathrm{C}$ in an electric furnace for 1 hour. For pastes, the chemically bound water content was calculated as the difference between the weight on ignition at $1050^{\circ} \mathrm{C}$ and the weight after oven drying at $105^{\circ} \mathrm{C}$.

The amount of calcium hydroxide $(\mathrm{CH})$ in the samples was determined by TG/DTA (thermogravimetry/differential thermal analysis). Analyses were conducted at a heating rate of $10^{\circ} \mathrm{C} / \mathrm{min}$ from $20^{\circ} \mathrm{C}$ to $1100^{\circ} \mathrm{C}$ under flowing nitrogen. The mass loss corresponding to the decomposition of $\mathrm{Ca}(\mathrm{OH})_{2}$ occurs between $440^{\circ} \mathrm{C}$ and $520^{\circ} \mathrm{C}$.

\subsection{The Amount of Calcium Hydroxide during the Hydration} Process. During the hydration of ordinary Portland cement, the amount of calcium hydroxide will increase until it reaches a steady state. During the hydration of cement-nanosilica blends, the evolution of the amount of $\mathrm{CH}$ depends on two factors: the Portland cement hydration that produces $\mathrm{CH}$ and the pozzolanic reaction that consumes $\mathrm{CH}$. In the initial period, the production of $\mathrm{CH}$ is the dominant process, and then the consumption of $\mathrm{CH}$ becomes the dominant process. In the experimental range, the amount of $\mathrm{CH}$ initially increases, reaches a maximum value, and then decreases. Using the experimentally determined calcium hydroxide content and chemically bound water content of Portland cement paste, the value of $\mathrm{RCH}_{\mathrm{CE}}$ in (6) was determined to be 0.23 , which means that $1 \mathrm{~g}$ of hydrated cement will produce $0.23 \mathrm{~g}$ of calcium hydroxide. Papadakis [10] also reported that when $1 \mathrm{~g}$ of cement hydrates, approximately $0.2 \sim 0.3 \mathrm{~g}$ of calcium hydroxide will be produced. Additionally, based on the experimentally determined calcium hydroxide contents in Portland cement paste and nanosilica blended cement paste, the value of $\mathrm{RCH}_{\mathrm{SF}}$ in (6) was determined to be 2.2 , which means that, for the pozzolanic reaction of nanosilica, $1 \mathrm{~g}$ of reacted nanosilica will consume $2.2 \mathrm{~g}$ of calcium hydroxide. Similarly, Maekawa et al. [9] proposed that when $1 \mathrm{~g}$ of silica fume reacts, $2 \mathrm{~g}$ of calcium hydroxide will be consumed during the pozzolanic reaction of silica fume.

A total of 12 series of experimental results regarding the calcium hydroxide contents and chemically bound water contents are presented in Figure 2 (calcium hydroxide contents) and Figure 3 (chemically bound water contents). The $w / b$ ratios of the specimens are 0.5 and 0.3 , and the nanosilica replacement ratios are $0 \%, 3 \%$, and $6 \%$.

Calibration process: in the calibration process, using calcium hydroxide contents for $w / b=0.5$ control specimen (shown in Figure 2(a)) and $w / b=0.5$ for the $3 \%$ nanosilica specimen (shown in Figure 2(c)), the reaction coefficients are calibrated. In this calibration process, 2 experimental results are used. The calibrated reaction coefficients of the proposed hydration model are shown in Table 4 . In this table, $B, C, k_{r}$, and $D_{e 0}$ are the reaction coefficients of cement and $k_{r s i}$ and $D_{e s i 0}$ are the reaction coefficients of nanosilica.

Validation process: in the validation process, the remaining experimental results, such as the calcium hydroxide contents and chemically bound water contents shown in Figures 2(b), 2(d) to 2(f), and 3(a) to 3(f), can be predicted. In this validation process, 10 experimental results are used. In the proposed model, the reaction coefficients do not vary with the nanosilica replacement ratios and water-to-binder ratios.

In summary, to use the proposed theoretical model, a small number of experimental results are required to calibrate the reaction coefficients. Furthermore, a large number of experimental results can be predicted. The time-consuming and expensive experimental investigations can be significantly reduced.

The evolution of the $\mathrm{CH}$ amount is shown as a function of the hydration time in Figure 2. As shown in Figure 2, the simulation results overall agree well with experimental results. When the water-to- binder ratios change from 0.5 (Figures 2(a), 2(c), and 2(e)) to 0.3 (Figures 2(b), 2(d), and $2(\mathrm{f})$ ), the amount of calcium hydroxide produced for $1 \mathrm{~g}$ of binder will decrease due to the reduction in capillary water and deposition space for hydration products. When the nanosilica replacement ratios increase from 0.03 (Figures $2(\mathrm{c})$ and $2(\mathrm{~d})$ ) to 0.06 (Figures 2(e) and 2(f)), the calcium hydroxide contents will correspondingly decrease due to the enhancement of the pozzolanic reaction of nanosilica. The proposed model can simulate the effects of the waterto-binder ratio and nanosilica replacement ratios on the hydration of Portland cement.

4.2. The Mass of Chemically Bound Water during Hydration Process. As proposed in the hydration model and reference [10], the chemically bound water mainly comes from the hydration of Portland cement. The pozzolanic reaction between calcium hydroxide and nanosilica occurs without additional water binding more than that contained in the $\mathrm{CH}$ 
TABLE 3: Mixing proportions of cement-nanosilica paste specimens.

\begin{tabular}{|c|c|c|c|c|c|}
\hline & \multirow{2}{*}{ Water-to-binder ratio (\%) } & \multicolumn{4}{|c|}{ Mixing proportions $\left(\mathrm{kg} / \mathrm{m}^{3}\right)$} \\
\hline & & Water & Cement & Nanosilica & AE water reducing agent \\
\hline \multirow{2}{*}{$\mathrm{OPC}$} & 30 & 486 & 1619 & - & \\
\hline & 50 & 612 & 1224 & - & \\
\hline \multirow{2}{*}{$\mathrm{OPC}+\mathrm{NS} 3$} & 30 & 486 & 1570 & 49 & Binder $* 0.8 \%$ \\
\hline & 50 & 612 & 1187 & 37 & Binder $* 0.5 \%$ \\
\hline \multirow{2}{*}{$\mathrm{OPC}+\mathrm{NS} 6$} & 30 & 486 & 1522 & 97 & Binder $* 1.6 \%$ \\
\hline & 50 & 612 & 1151 & 73 & Binder $* 1.0 \%$ \\
\hline
\end{tabular}

TABLE 4: Reaction coefficients of the proposed hydration model.

\begin{tabular}{lccccc}
\hline$B(\mathrm{~cm} / \mathrm{h})$ & $C(\mathrm{~cm} / \mathrm{h})$ & $k_{r}(\mathrm{~cm} / \mathrm{h})$ & $D_{e 0}\left(\mathrm{~cm}^{2} / \mathrm{h}\right)$ & $k_{r s i}(\mathrm{~cm} / \mathrm{h})$ & $D_{e s i 0}\left(\mathrm{~cm}^{2} / \mathrm{h}\right)$ \\
\hline $4.310 * 10^{-7}$ & 0.035 & $1.073 * 10^{-5}$ & $5.474 * 10^{-8}$ & $1.00 * 10^{-6}$ & $2.50 * 10^{-13}$ \\
\hline
\end{tabular}

molecules. The evolution of the mass of bound water is shown as a function of the hydration time in Figure 3. As shown in Figure 3, the simulated results overall agree well with the experimental results. When the water-to-binder ratios change from 0.5 (Figures 3(a), 3(c), and 3(e)) to 0.3 (Figures 3(b), 3(d), and 3(f)), the chemically bound water produced for $1 \mathrm{~g}$ of binder will decrease due to the reduction in capillary water and deposition space for hydration products.

As shown in Figures 2 and 3, the analysis results can generally reproduce the experimental results. However, for some cases (Figures 2(e), 2(f), 3(b), 3(d), and 3(f)), the modeling results show disagreements with the experimental results. These differences arise from the following reasons.

When calculating the calcium hydroxide contents in pastes with higher nanosilica replacement levels (Figures 2(e) and 2(f), nanosilica replacement 6\%), due to the increase in nanosilica contents, the surface area of cement-based materials will increase significantly. In this case, increasing the superplasticizer content to lubricate the nanosilica particles and to break the agglomerates, that is, $6 \%$ nanosilica, is difficult because of the very large specific surface area of nanosilica. Nanosilica will slightly agglomerate, and the pozzolanic reaction will be delayed. The agglomeration of nanosilica is not considered in the proposed model. Therefore, for pastes with higher nanosilica contents, the peaks in the analysis results occur earlier than in the experimental results.

When calculating the chemically bound water contents in pastes with lower water-to-binder ratios (Figures 3(b), 3(d), and $3(\mathrm{f})$, water-to-binder ratio 0.3 ), due to the decrease in water-to-binder ratios, the degree of supersaturation of the pore solution will increase and the initial dormant period of the paste will be shortened. The hydration reaction will correspondingly be accelerated. The proposed model does not take into account the influences of ion concentrations or the degree of supersaturation of the pore solution on the hydration kinetics of cement-based materials. Therefore, for pastes with lower water-to-binder ratios, the analysis results for the early age are slightly lower than the experimental results.
Hence, at the current stage, the model is not perfect because some variables are not accounted for; thus, the model will be subjected to further improvements in the future.

4.3. The Evaluation of Compressive Strength. It is well known that the compressive strength of concrete depends on the gel/space ratio determined from the degree of cement hydration and the $w / c$ ratio. The gel/space ratio is defined as the ratio of the volumes of the hydrated cement to the sum of the volumes of the hydrated cement and of the capillary pores [15]. For Portland cement pastes, it is approximately assumed that $1 \mathrm{~mL}$ of hydrated cement occupies $2.06 \mathrm{~mL}$, and, for the nanosilica pozzolanic reaction, $1 \mathrm{~mL}$ of reacted nanosilica is considered to occupy $2.52 \mathrm{~mL}$ of space [15]. Therefore, the $\mathrm{gel} /$ space ratio of cement-nanosilica paste is given by

$$
x_{f c}=\frac{2.06(1 / \rho) \alpha C_{0}+2.52\left(1 / \rho_{s i}\right) \alpha_{\text {silica }} m_{\text {silica } 0}}{(1 / \rho) \alpha C_{0}+\left(1 / \rho_{\text {si }}\right) \alpha_{\text {silica }} m_{\text {silica } 0}+W_{0}}
$$

where $x_{f c}$ is the gel/space ratio of blended cement pastes. Note that the volume change of nanosilica is larger than that of the anhydrous cement (2.52 versus 2.06 ). This result may partially be due to the lower density of the pozzolanic hydration products and may indicate that pozzolanic reaction products are more effective in filling pores [15].

Furthermore, the development of compressive strength in blended concrete can be evaluated through Powers' strength theory as

$$
\begin{gathered}
f_{c}=A x_{f c}^{n}, \\
A=a \frac{C_{0}}{C_{0}+m_{\text {silica0 }}}+b \frac{m_{\text {silica } 0}}{C_{0}+m_{\text {silica } 0}}
\end{gathered}
$$

where $f_{c}$ is the compressive strength of blended concrete. $A$ is the intrinsic strength of the material and can be expressed as a function of the weight fractions of cement and mineral admixture in the mixing proportion. The coefficients $a$ and $b$ in (10b) represent the contributions of cement and mineral admixture to the intrinsic strength of materials, respectively, and the units of $a$ and $b$ are MPa. $n$ is the exponent. 


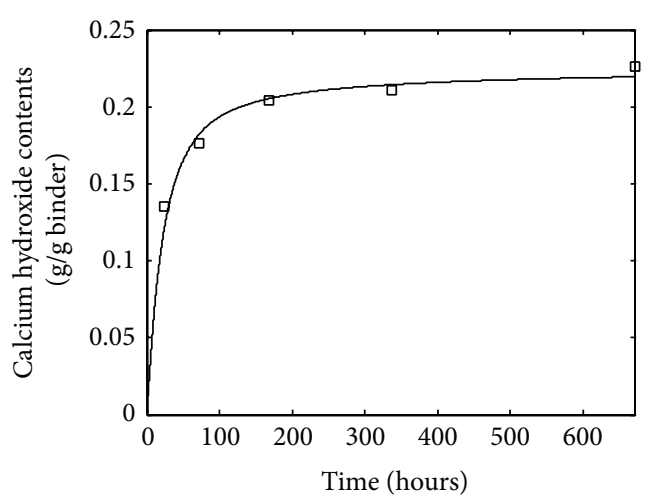

Analysis results of OPC 0.5

$\square \quad$ Experimental results of OPC 0.5

(a) OPC paste with water-to-cement ratio 0.5

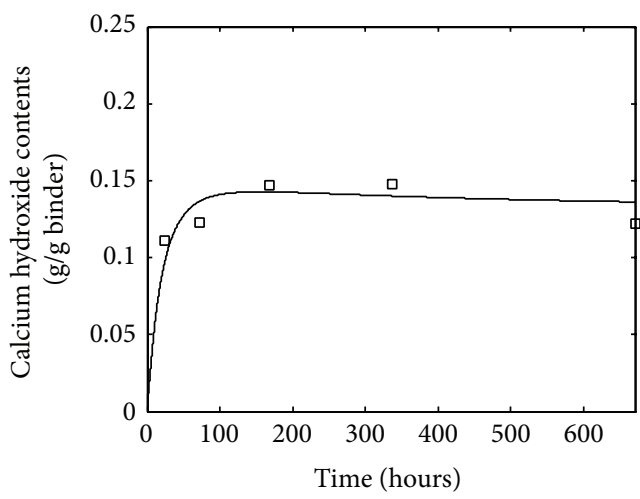

_ Analysis results of OPC 0.5 and NS 3\%

$\square \quad$ Experimental results of OPC 0.5 and NS 3\%

(c) OPC-nanosilica paste with water-to-binder ratio 0.5 and $3 \%$ nanosilica

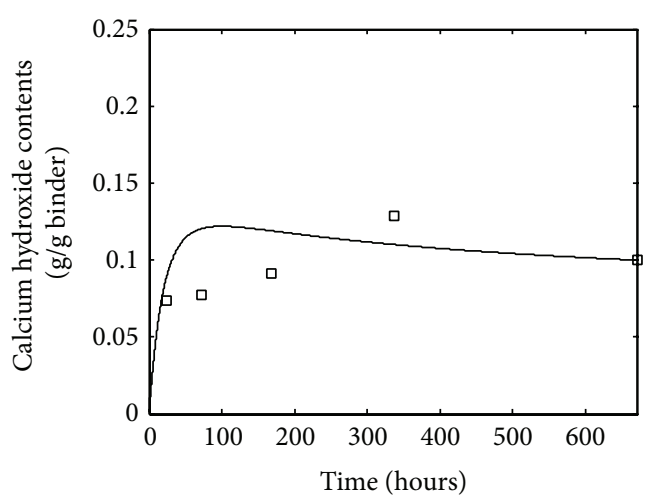

- Analysis results of OPC 0.5 and NS 6\%

$\square \quad$ Experimental results of OPC 0.5 and NS $6 \%$

(e) OPC-nanosilica paste with water-to-binder ratio 0.5 and $6 \%$ nanosilica

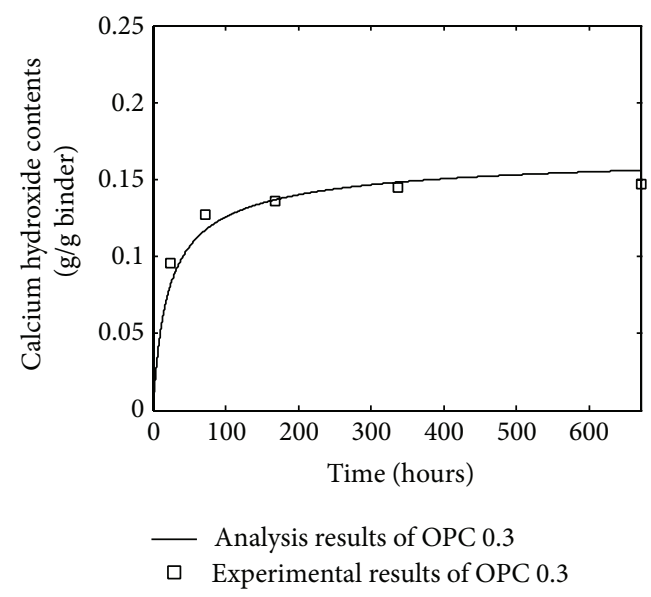

(b) OPC paste with water-to-cement ratio 0.3

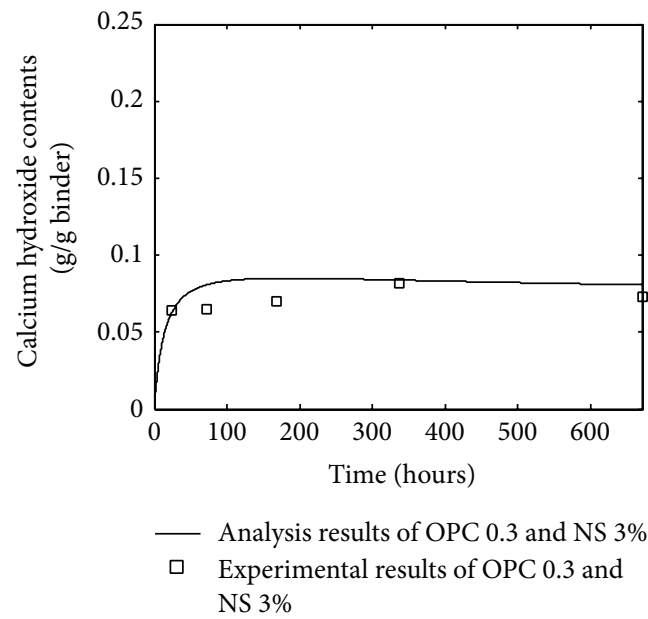

(d) OPC-nanosilica paste with water-to-binder ratio 0.3 and $3 \%$ nanosilica

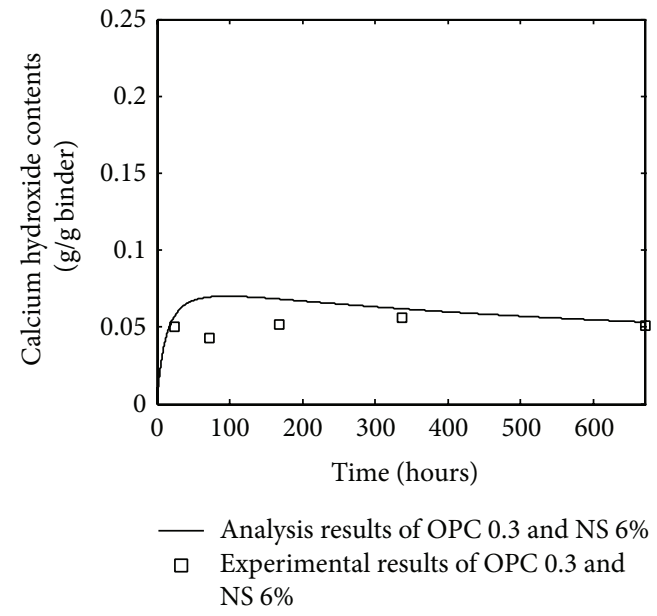

(f) OPC-nanosilica paste with water-to-binder ratio 0.3 and $6 \%$ nanosilica

FIGURE 2: Evaluation of calcium hydroxide contents. 


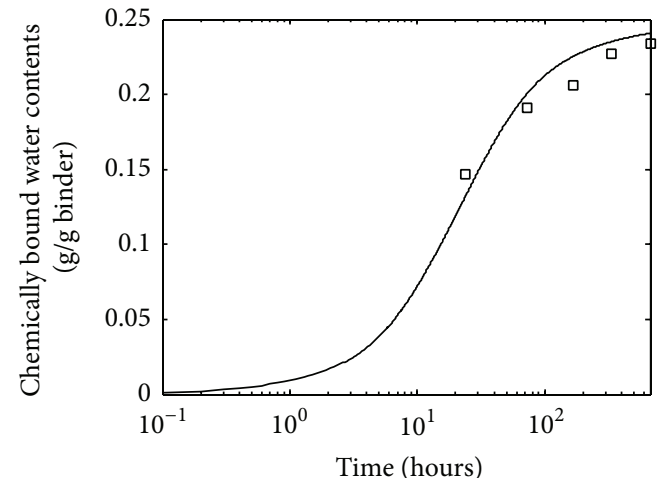

- Analysis results of OPC 0.5

$\square \quad$ Experimental results of OPC 0.5

(a) OPC paste with water-to-cement ratio 0.5

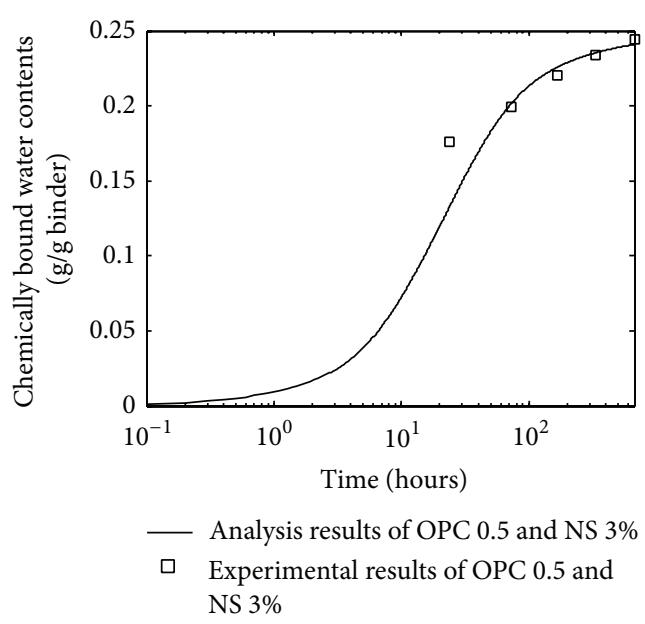

(c) OPC-nanosilica paste with water-to-binder ratio 0.5 and $3 \%$ nanosilica

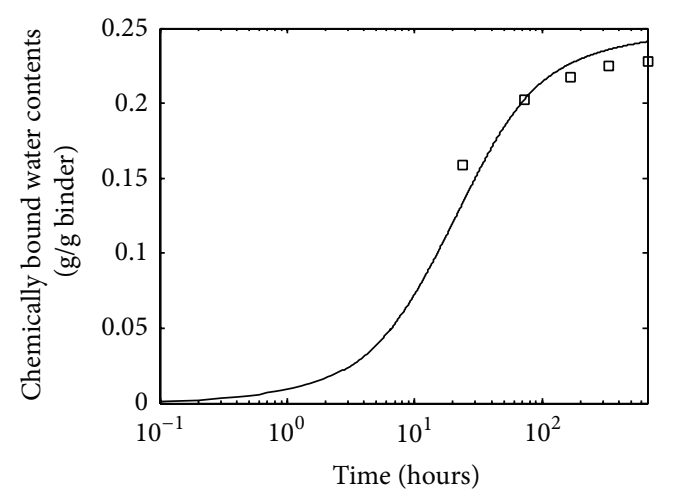

- Analysis results of OPC 0.5 and NS 6\%

$\square \quad$ Experimental results of OPC 0.5 and NS $6 \%$

(e) OPC-nanosilica paste with water-to-binder ratio 0.5 and $6 \%$ nanosilica

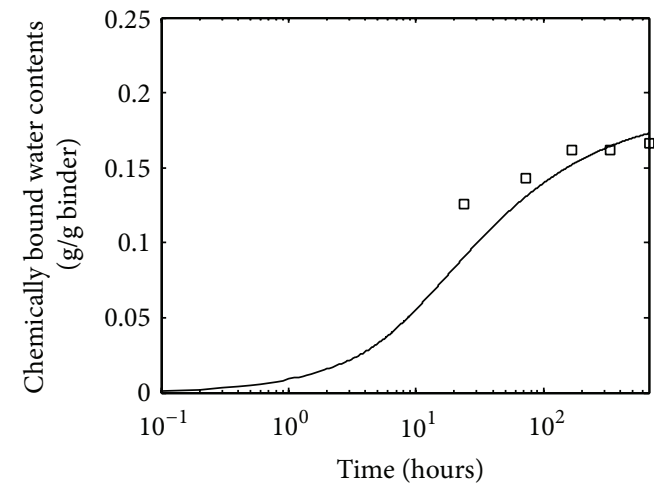

- Analysis results of OPC 0.3

$\square \quad$ Experimental results of OPC 0.3

(b) OPC paste with water-to-cement ratio 0.3

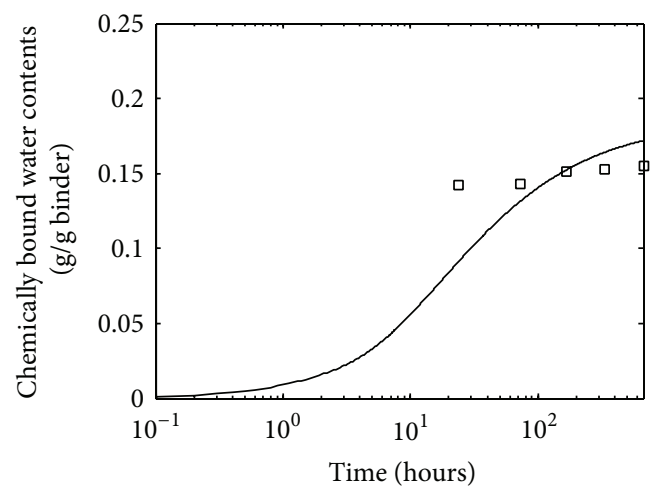

_ Analysis results of OPC 0.3 and NS 3\%

$\square \quad$ Experimental results of OPC 0.3 and NS 3\%

(d) OPC-nanosilica paste with water-to-binder ratio 0.3 and $3 \%$ nanosilica

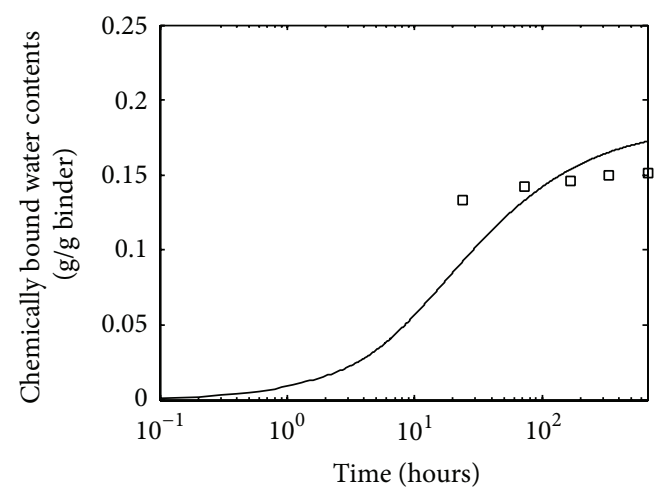

— Analysis results of OPC 0.3 and NS 6\%

$\square \quad$ Experimental results of OPC 0.3 and NS 6\%

(f) OPC-nanosilica paste with water-to-binder ratio 0.3 and $6 \%$ nanosilica

FIgURE 3: Evaluation of chemically bound water contents. 


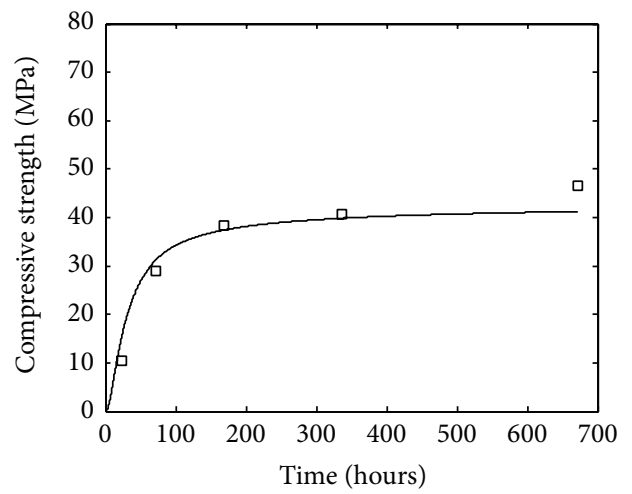

— Analysis results of OPC 0.5

口 Experimental results of OPC 0.5

(a) OPC paste with water-to-cement ratio 0.5

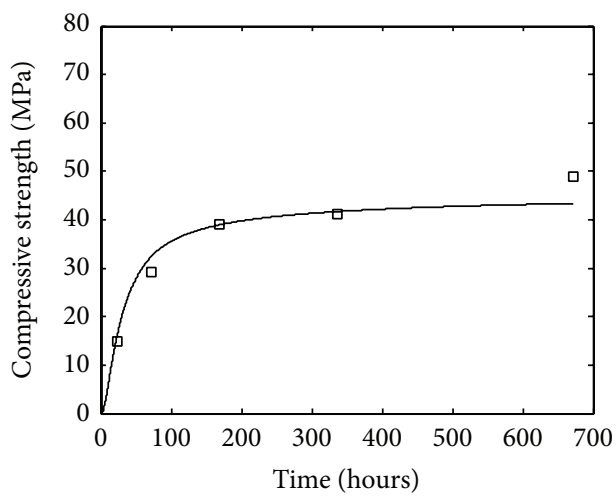

- Analysis results of OPC 0.5 and NS 3\%

$\square$ Experimental results of OPC 0.5 and NS $3 \%$

(c) OPC-nanosilica paste with water-to-binder ratio 0.5 and $3 \%$ nanosilica

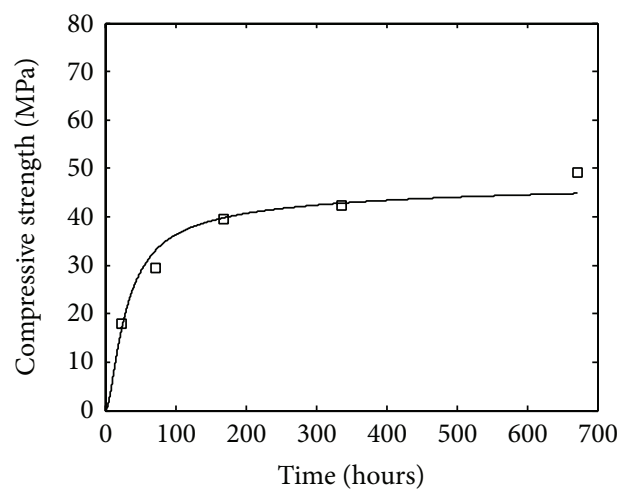

Analysis results of OPC 0.5 and NS 6\%
Experimental results of OPC 0.5 and
NS 6\%

(e) OPC-nanosilica paste with water-to-binder ratio 0.5 and $6 \%$ nanosilica

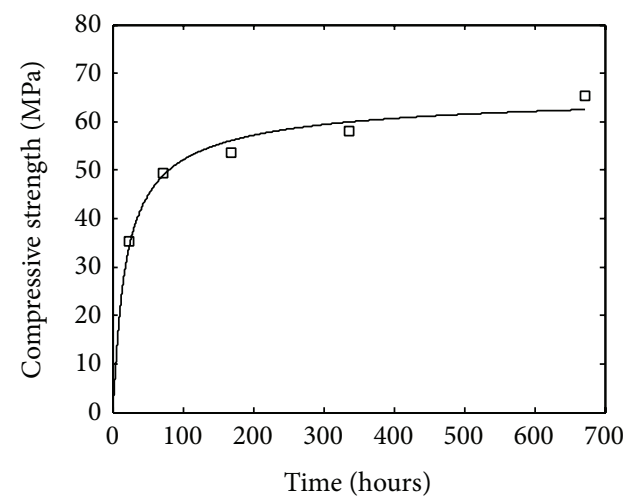

— Analysis results of OPC 0.3

口 Experimental results of OPC 0.3

(b) OPC paste with water-to-cement ratio 0.3

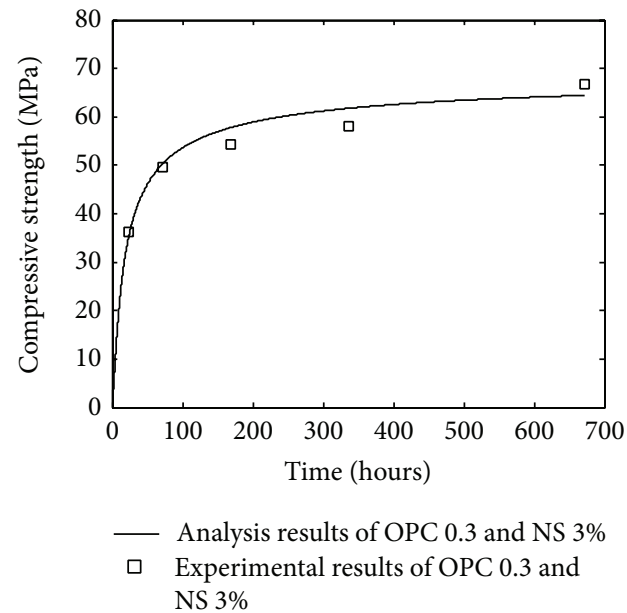

(d) OPC-nanosilica paste with water-to-binder ratio 0.3 and $3 \%$ nanosilica

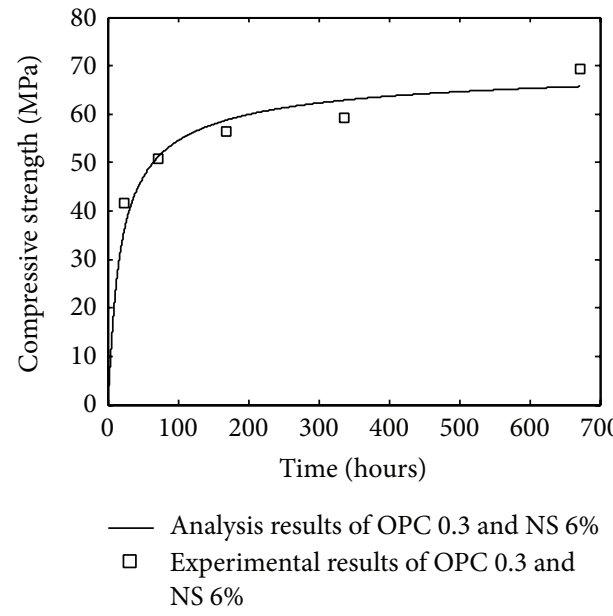

(f) OPC-nanosilica paste with water-to-binder ratio 0.3 and $6 \%$ nanosilica

FIgURE 4: Evaluation of compressive strength developments. 
Based on the compressive strength of nanosilica blended paste, the values of the coefficients of $a$ and $b$ are given as $a=128$ and $b=160$, and $n=3.0$ (water/binder $=0.5$ ) and $n=$ 2.3 (water/binder $=0.3$ ). The decrease in $n$ may be attributed to the homogenization of hydration products for specimens with lower water-to-binder ratios [15]. Comparisons between the experimental results and the prediction results are shown in Figure 4. Compared with the control specimens (Figures 4(a) and 4(b)), at an early age of 1 day, the compressive strength of nanosilica blended paste (Figures 4(c) to 4(f)) is significantly increased. In contrast, at the late age of 28 days, the compressive strength of nanosilica blended paste is only slightly higher than that of the control specimens. $\mathrm{Li}$ et al. [2] also obtained similar results: for nanosilica blended paste, the extent of the compressive strength enhancement is considerably more significant at an early age.

\section{Conclusions}

This paper presents the results from experimental investigations and theoretical modeling of the hydration reaction of nanosilica blended concrete. The contents of chemically bound water in nanosilica blended paste are similar to those in the control specimens, which means that the pozzolanic reaction of nanosilica does not produce chemically bound water. Due to the pozzolanic reaction of nanosilica, the contents of calcium hydroxide in nanosilica blended paste are much lower than those in the control specimens. Compared with the control specimens, the extent of compressive strength enhancement in nanosilica blended specimens is considerably higher at early ages.

A numerical model is proposed to simulate the hydration of concrete containing nanosilica. The reaction coefficients of nanosilica are obtained from the experimentally determined calcium hydroxide contents in nanosilica blended concrete. The degree of hydration of cement and the degree of reaction of nanosilica are calculated to accompany the results from the proposed hydration model. The development of compressive strength in nanosilica blended paste is evaluated using the gel-space ratio, which considers the contributions of cement hydration and the nanosilica reaction. The calculated results regarding chemically bound water, calcium hydroxide, and compressive strength generally agree with the experimental results.

\section{Conflict of Interests}

The authors declare that there is no conflict of interests regarding the publication of this paper.

\section{Acknowledgment}

This study was financially supported by the National Research Foundation of Korea (Grant no. NRF-2013R1A1A2060231; Project name: An Integrated Program for Predicting Chloride Penetration into Reinforced Concrete Structures by Using a Cement Hydration Model).

\section{References}

[1] P. Zhang, Q. Y. Guan, C. H. Liu, and Q. F. Li, "Study on notch sensitivity of fracture properties of concrete containing Nano$\mathrm{SiO}_{2}$ particles and fly ash," Journal of nanomaterials, vol. 2013, Article ID 381682, 7 pages, 2013.

[2] H. Li, H. Xiao, J. Yuan, and J. Ou, "Microstructure of cement mortar with nano-particles," Composites Part B: Engineering, vol. 35, no. 2, pp. 185-189, 2004.

[3] M. Zhang and H. Li, "Pore structure and chloride permeability of concrete containing nano-particles for pavement," Construction and Building Materials, vol. 25, no. 2, pp. 608-616, 2011.

[4] T. Ji, "Preliminary study on the water permeability and microstructure of concrete incorporating nano- $\mathrm{SiO}_{2}$," Cement and Concrete Research, vol. 35, no. 10, pp. 1943-1947, 2005.

[5] B. Jo, C. Kim, G. Tae, and J. Park, "Characteristics of cement mortar with nano- $\mathrm{SiO}_{2}$ particles," Construction and Building Materials, vol. 21, no. 6, pp. 1351-1355, 2007.

[6] S. Swaddiwudhipong, H. Wu, and M. H. Zhang, "Numerical simulation of temperature rise of high-strength concrete incorporating silica fume and superplasticiser," Advances in Cement Research, vol. 15, no. 4, pp. 161-169, 2003.

[7] S. Tanaka, K. Inoue, Y. Shioyama, and R. Tomita, "Methods of estimating heat of hydration and temperature rise in blast furnace slag blended cement," Materials Journal, vol. 92, no. 4, pp. 429-436, 1995.

[8] G. De Schutter and L. Taerwe, "General hydration model for portland cement and blast furnace slag cement," Cement and Concrete Research, vol. 25, no. 3, pp. 593-604, 1995.

[9] K. Maekawa, T. Ishida, and T. Kishi, Multi-Scale Modeling of Structural Concrete, Taylor \& Francis, London, UK, 2009.

[10] V. G. Papadakis, "Experimental investigation and theoretical modeling of silica fume activity in concrete," Cement and Concrete Research, vol. 29, no. 1, pp. 79-86, 1999.

[11] F. Tomosawa, T. Noguchi, and C. Hyeon, "Simulation model for temperature rise and evolution of thermal stress in concrete based on kinetic hydration model of cement," in Proceedings of the 10th International Congress on the Chemistry of Cement, pp. 72-75, Gothenburg, Sweden, 1997.

[12] F. Tomosawa, "Development of a kinetic model for hydration of cement," in Proceedings of the 10th International Congress Chemistry of Cement, pp. 51-58, Gothenburg, Sweden, 1997.

[13] P. Lura, O. M. Jensen, and K. Van Breugel, "Autogenous shrinkage in high-performance cement paste: an evaluation of basic mechanisms," Cement and Concrete Research, vol. 33, no. 2, pp. 223-232, 2003.

[14] T. Saeki and P. J. M. Monteiro, "A model to predict the amount of calcium hydroxide in concrete containing mineral admixtures," Cement and Concrete Research, vol. 35, no. 10, pp. 1914-1921, 2005.

[15] X. Wang and H. Lee, "Modeling the hydration of concrete incorporating fly ash or slag," Cement and Concrete Research, vol. 40, no. 7, pp. 984-996, 2010. 

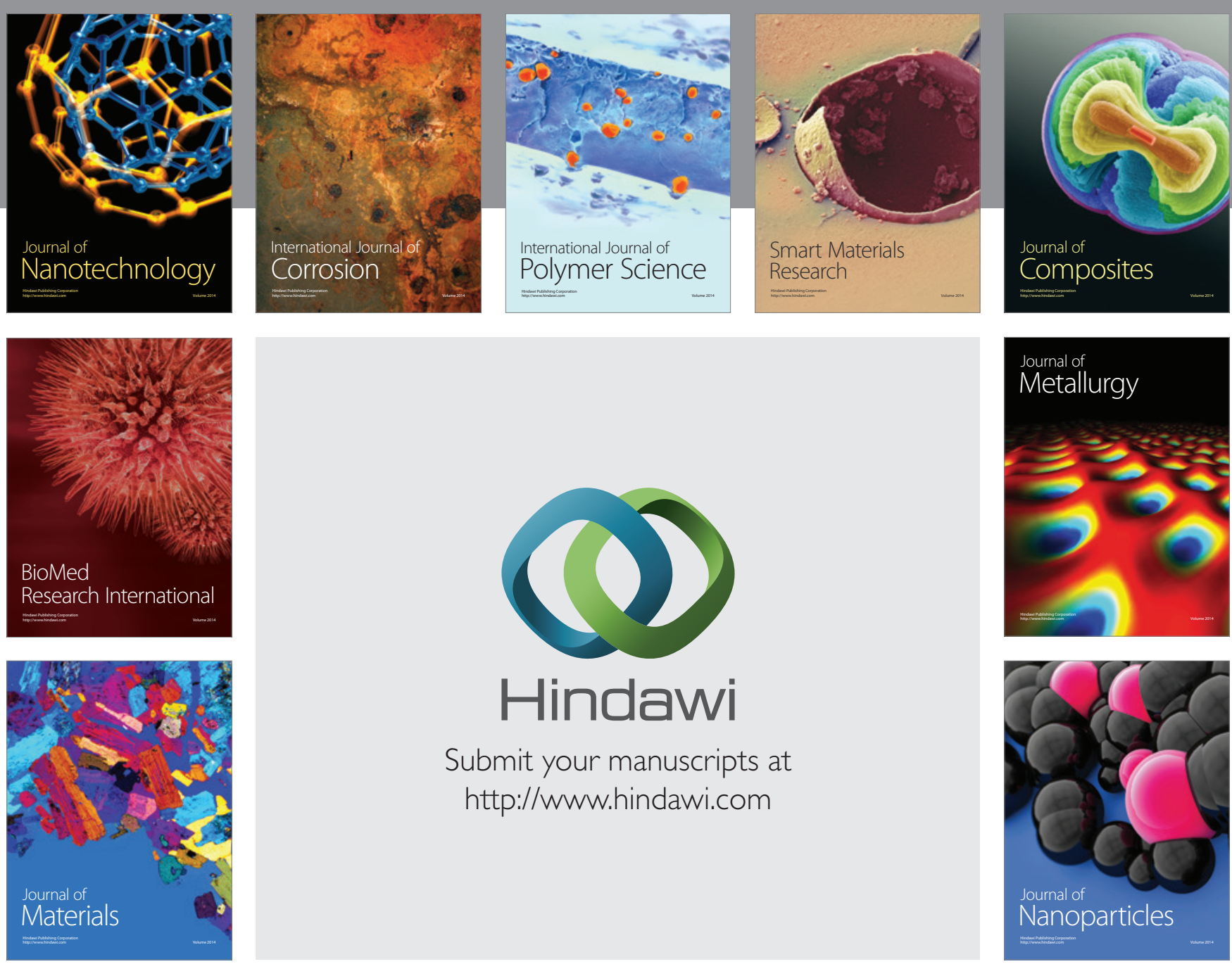

Submit your manuscripts at http://www.hindawi.com
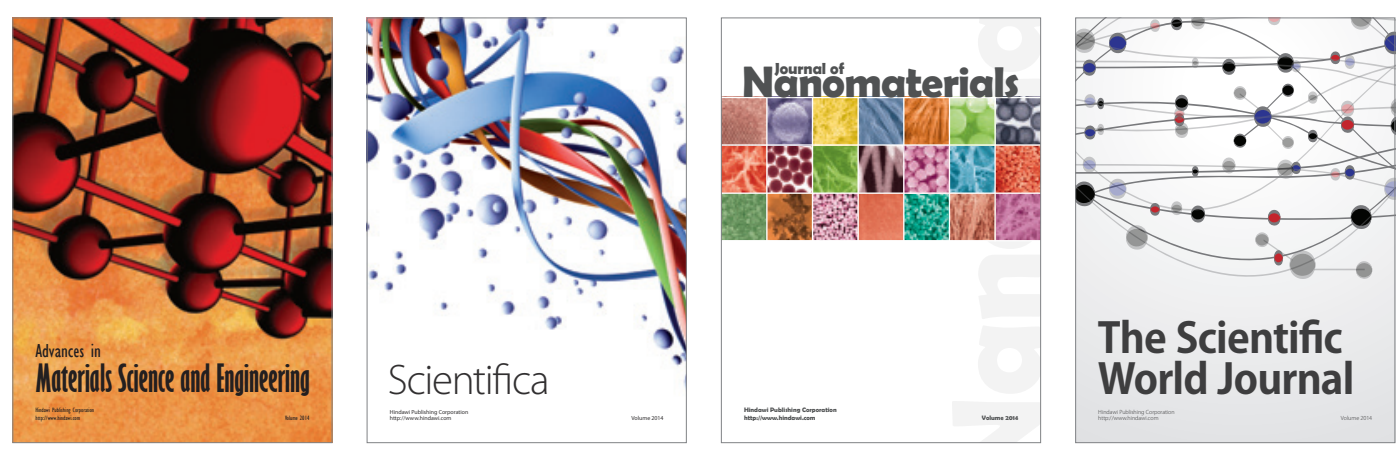

\section{The Scientific World Journal}
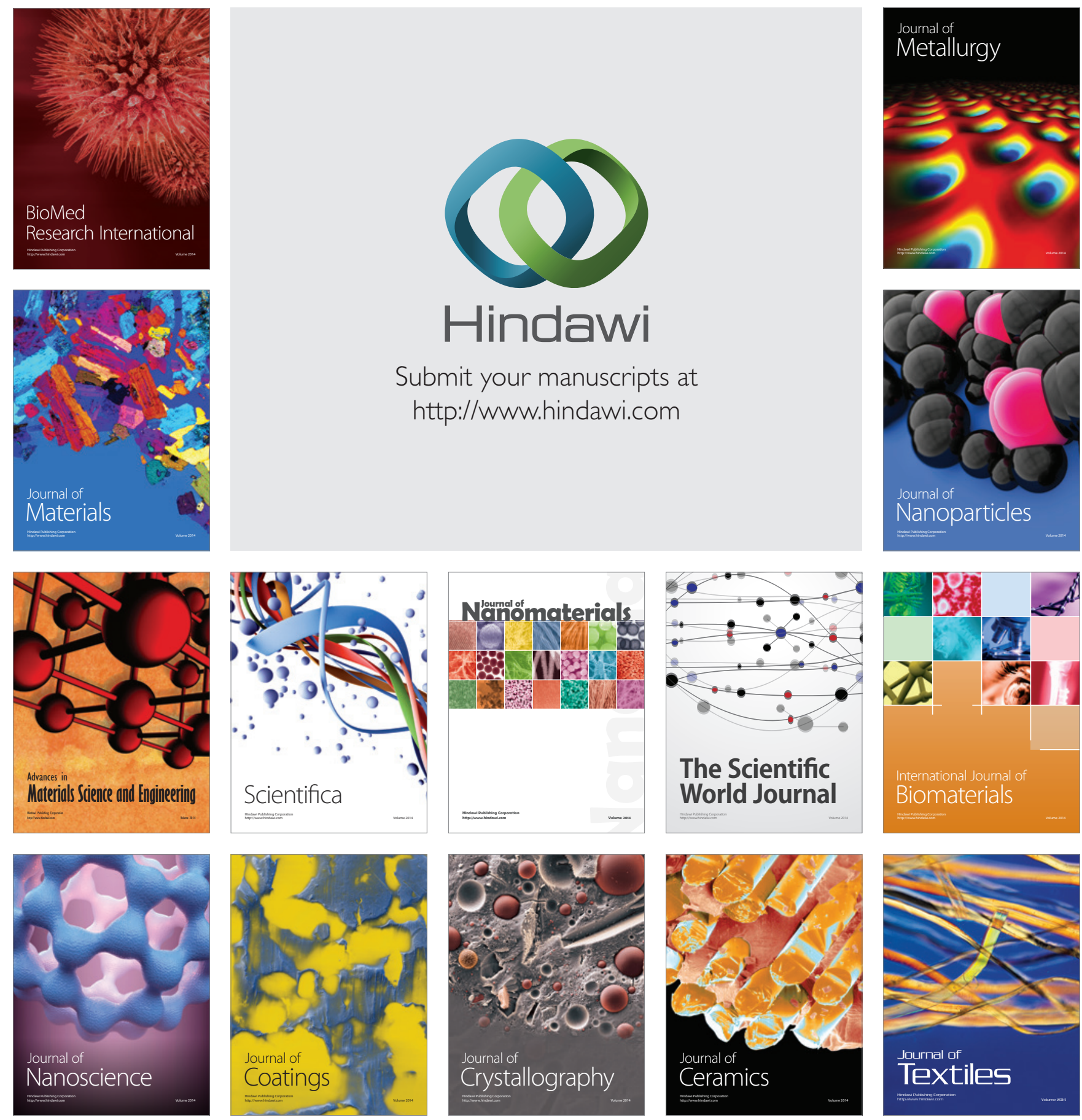